\title{
Disorders of galactose metabolism
}

\author{
V. SCHWARZ \\ From the Departments of Medical Biochemistry and Child Health, \\ University of Manchester
}

Galactosaemia, in its generic sense, stems from a failure to metabolize galactose. The inability may be inherited and permanent, as in the case of a specific enzyme deficiency, or it may be acquired and temporary, as in cirrhosis or hepatitis. But although the aetiology of these conditions is different, the pathogenesis may be similar, a fact which should be reflected in the treatment. Although there is some evidence that galactose as such is not toxic, its metabolism may give rise to toxic compounds or may deprive the cell of vital intermediates. It seems reasonable, therefore, that we should treat all galactosaemias by rigidly excluding lactose from the diet.

In the metabolism of galactose the following established reactions are important (Fig. 1).

$1 \mathrm{Gal}+$ ATP $\rightarrow$ Gal-1-P + ADP

2 Gal-1-P + UDP Gluc. $\rightleftharpoons$ Gluc-1-P + UDP-Gal.

3 UDP-Gal $\rightleftharpoons$ UDP-Gluc.

4 Gluc-1-P + UTP $\rightleftharpoons$ UDP-Gluc + PP

5 Gal-1-P + UTP $\rightleftharpoons$ UDP-Gal + PP

6 Gal-6-P + NADP $\rightarrow$ 6-P-Galactonate + NADPH

7 Gal + NAD $\rightarrow$ Galactonolactone $\rightarrow$ Galactonate $\rightarrow \beta$ ketogalactonate $\rightarrow$ xylulose

$8 \mathrm{Gal}+$ NADPH $\rightarrow$ Galactitol + NADP.

The first four reactions are the major routes by which galactose is metabolized and it is in this group that hereditary deficiencies have been described. Reaction 4 constitutes the synthesis of UDP glucose, an intermediate without which neither glycogen nor mucopolysaccharides could be synthesized nor glucose introduced into a variety of compounds. Thus absence of the enzyme, UDP glucose pyrophosphorylase, is probably incompatible with viability and has not been described. By reaction 3, ? similarly, UDP galactose is synthesized and in the absence of dietary galactose it is therefore on this reaction that the synthesis of galactose-containing compounds depends. Again it is unlikely that higher organisms would be viable without this enzyme, UDP galactose-4-epimerase.

The two other enzymes do not play such a vital role and their absence constitutes what we maß describe as the hereditary galactosaemias, althoug 8 usually this term is reserved for the older and s. far much more common galactose-1-P uridyl trans $=$ ferase deficiency (reaction 2) which leads to the accumulation of galactose-1-phosphate in the cells. Recently a galactokinase deficiency (reaction 1) has been described by Gitzelmann $(1965,1967)$ and the clinical manifestations of this disease are especially interesting in relation to the pathogenesis of the more common hereditary galactosaemia (see below).
Galactokinase

Galactose-1-P Uridyl transferase

UDP-Galactose

4 - epimerase

UDP-Glucose pyrophorylase

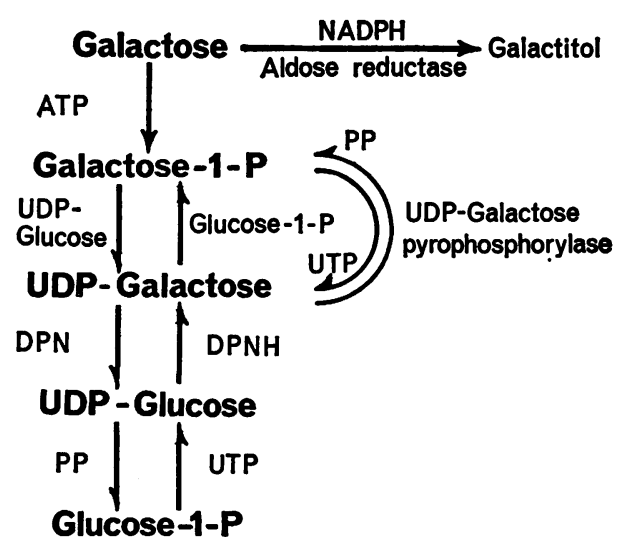

FIG. 1. Main pathways of galactose metabolism. Gal = galactose, Gal-1-P = galactose 1-phosphate, Gluc $=$ glucose, Gluc-1-P = glucose 1-phosphate, $A T P=$ adenosine triphosphate, $A D P=$ adenosine diphosphate, $U D P=$ uvidine disphospho-, UTP-uridine triphosphate, $P P=$ pyrophosphate, $N A D=$ nicotinamide-adenine dinucleotide, $N A D P=N A D$ phosphate, $N A D P H=$ reduced $N A D P$. 
The latter condition is due to the complete or almost complete absence of galactose-1-P uridyl transferase. ${ }^{1}$ In 1958 we estimated the incidence of galactosaemia in Great Britain to be about 1 in 65,000 live births, on the basis of the numbers of cases diagnosed in the whole country and in the Manchester area in the preceding few years. Determinations of heterozygote frequency have yielded an incidence of galactosaemia of 1:40,000 with an upper limit of $1: 19,000$ (Hansen, Bretthauer, Mayes, and Nordin, 1964). It seems likely, therefore, that some cases are being missed, remaining undiagnosed either on account of perinatal death or of unusually mild symptoms.

Many different assays and diagnostic tests have been proposed and most of them are quite adequate for the detection of homozygotes. We still use the micro-manometric test I described some years ago (Schwarz, 1960a), which we have modified for greater convenience. We now prepare several dozen sets of tubes at a time by charging them with the reagents, and are able to dry and store them in the deep-freeze for years without loss of reactivity. It is necessary only to add the washed haemolysed blood cells to carry out a diagnostic test which takes about 15 minutes' working time.

Treatment by restricting galactose intake is fairly straightforward although all brands of low-lactose milk available commercially contain some lactose, and casein itself, which is the chief protein of the preparation, has galactose in its molecule. Hence there is clearly a limit below which one cannot reduce the galactose intake by the use of such diets. Soya preparations are free from lactose but contain rather large amounts of $a$-galactosides which, though not hydrolysed by lactase, may be hydrolysed by the intestinal flora.

Later, when the infant is put on a mixed diet, there are greater dangers. Lactose lurks in many places such as breakfast cereals, bread, cake, biscuits, tinned foods, margarine, tablets made up with lactose as a filler, etc. We set great store by a regular determination of red cell galactose-1-phosphate, which is an invaluable guide to a patient's galactose intake.

The patient C.W. was diagnosed at 3 weeks of age and has been tested regularly since. Figure 2 shows the galactose-1-phosphate content of his erythrocytes compared with that of another patient, M.F., diagnosed at birth. C.W.'s galactose-1-phosphate level fell only slowly and then suddenly rose. It was obvious that he was receiving some galactose in his

\footnotetext{
${ }^{1}$ A condition of partial gal-1-P uridyl transferase deficiency has been described by Beutler, Baluda, Sturgeon, and Day (1965) under the name 'Duarte variant'. In this condition, which does not appear to be associated with any clinical abnormality, the red cell enzyme level is about $50 \%$ of normal in homozygotes and $75 \%$ in heterozygotes. ED.
}

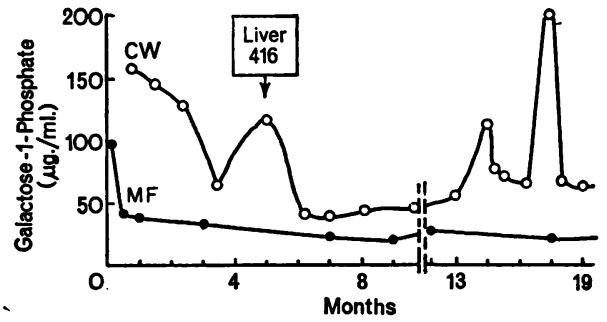

FIG. 2. Galactose-1-phosphate in red cells of two galactosaemic patients diagnosed at birth (M.F.) and at 3 weeks (C.W.).

diet. At 5 months a biopsy showed the liver to be cirrhotic and to contain $416 \mu \mathrm{g}$ galactose-1-phosphate/g wet tissue. Eventually we traced the offending article in his diet, a lactose-containing cereal, and the galactose-1-phosphate level began to fall. Since then it has fluctuated, rising to high peaks after periods at home (his parents are illiterate) and falling to more acceptable levels during spells in hospital.

Another patient (C.B.), also diagnosed at 3 weeks when her red cell galactose-1-phosphate was 350 $\mu \mathrm{g} / \mathrm{ml}$, developed normally apart from partial deafness due possibly to jaundice in the neonatal period. A regular check of her galactose-1-phosphate showed levels around $45 \mu \mathrm{g} / \mathrm{ml}$ until at 6 years she developed mild hepatitis: she became jaundiced, liver function became abnormal and the red cell galactose-1-phosphate rose to $78 \mu \mathrm{g} / \mathrm{ml}$. A liver biopsy contained $260 \mu \mathrm{g} / \mathrm{g}$ and indicated cirrhosis. After the hepatitis the red cell galactose-1-phosphate level remained high ( 75 to $100 \mu \mathrm{g} / \mathrm{ml}$ ).Two years later splenectomy was performed to relieve portal hypertension and her condition improved. The latest red cell galactose-1-phosphate level was $185 \mu \mathrm{g} / \mathrm{ml}$. It seems likely that some of this patient's original galactose-metabolizing potential has been lost through further damage to a cirrhotic liver by the hepatitis.

Patient R.G. seemed to be well controlled, both clinically and biochemically, until at 1 year 4 months the red cell galactose-1-phosphate rose to $74 \mu \mathrm{g} / \mathrm{ml}$ and was still $61 \mu \mathrm{g} / \mathrm{ml}$ two months later. Eventually we discovered that she was eating bread containing a small amount of milk. When home-made bread was substituted the galactose-1-phosphate level dropped below $50 \mu \mathrm{g} / \mathrm{ml}$.

Another patient, T.L., was diagnosed at 5 weeks. He was put on a low-lactose milk and 10 days later his galactose-1-phosphate level was still $188 \mu \mathrm{g} / \mathrm{ml}$ which dropped only slowly during the next five weeks to $106 \mu \mathrm{g} / \mathrm{ml}$. His liver function is abnormal 
and he has small haemorrhages. After a careful analysis of his diet we have tentatively concluded that cirrhosis must have progressed to the point where his liver is unable to cope satisfactorily even with the small amounts of lactose unavoidably present in his diet.

These examples should demonstrate the importance of monitoring the patient's galactose-1phosphate as an indicator of galactose intake and as a warning of liver and particularly brain damage, which a reliance on clinical evidence may be too late to prevent.

Galactose-1-phosphate probably accumulates in all tissues (Schwarz, 1960b) and since it inhibits a number of enzymes in vitro, including phosphoglucomutase and glucose-6-P dehydrogenase, it was widely assumed that the toxicity of the phosphate could account for the pathogenesis of galactosaemia. But van Heyningen (1959) reported some years ago that experimental sugar cataract in rats was associated with accumulation in the lens of hexitols formed by reduction of the sugars with the aid of aldose reductase and NADPH. Thus galactose gives rise to galactitol (reaction 8), and in diabetic cataract glucose gives rise to sorbitol. These hexitols are formed only slowly at physiological hexose concentrations but very much faster at higher concentrations, and since the cell membrane is largely impermeable to them, water will flow into the tissues to maintain osmolarity. Further, since galactose competes with oxidized glutathione for the available NADPH, this would explain the loss of reduced glutathione which is one of the earliest biochemical changes in galactose cataract, together with the rise in peroxide and oxidation of protein SH groups. These physical and chemical changes probably lead to interference with normal metabolism, and possibly to a disruption of fibres in the lens resulting in opacification.

The demonstration by Wells, Pittmann, and Egan (1964) of excretion of galactitol in the urine of a galactosaemic patient was quickly followed by reports of the presence of galactitol in the tissues. Brain contained $4 \mathrm{mg} / \mathrm{g}$ of wet weight, or more than $2 \%$ of the dry weight.

More recently Stewart, Sherman, Kurien, Moonsammy, and Wisgerhof (1967) showed that in rats fed on a high galactose diet the highest concentration of galactitol is to be found in nerve. In this tissue the myo-inositol concentration was markedly depressed to one quarter of the level found in control animals, an observation attributable to the inhibition of inositol synthesis by galactitol (Wells and Wells, 1967). Gabbay and O'Sullivan (1968) reported that the aldose reductase in nervous tissue is located in the Schwann cell, the site of damage in diabetic neuropathy.

Evidence is thus mounting which incriminates hexitols, or metabolic changes resulting from their formation, in the pathogenesis of both galactosaemia and diabetes. In the former galactose-1phosphate may still play a part, as may perhaps other toxic products of galactose metabolism not yet recognized. The sibs suffering from a galactokinase deficiency reported by Gitzelmann (1967) excreted large amounts of galactitol. All have cataracts, which presumably cannot be due to galactose1-phosphate as this is not present in excess; on the other hand they appear to be of normal intelligence, as far as this can be assessed in blind gipsies, and the liver and kidney are not affected. Although more cases will have to be studied, the present findings suggest that galactitol may not be the only or even the most important cause of the mental retardation seen in galactosaemia.

Whatever the precise mechanisms of the pathogenesis, the progression of the galactosaemias clearly depends on the dietary intake of galactose. It might be expected that the infant diagnosed at or soon after birth would develop perfectly normally if galactose were withheld. However, on the few occasions when we have determined galactose-1phosphate in the red cells of a galactosaemic infant at birth, we have found relatively large concentrations. In one patient the initial level of $70 \mu \mathrm{g} / \mathrm{ml}$ rose to 100 after two days and then steadily declined (Fig. 2). Clearly, the galactose must have diffused across the placenta. How much damage is done to the developing brain in utero, or after birth, through avoidable or unavoidable exposure to galactose, we do not know, but the impression among paediatricians is gaining ground that the IQ even of infants diagnosed at birth is below average.

Segal, Blair, and Topper (1962) used labelled galactose to investigate eight subjects who satisfied all the usual diagnostic criteria of hereditary galactosaemia, including the absence of uridyl transferase from the red cells, liver disease, failure to thrive, and cataracts. Two of these were found to produce ${ }^{14} \mathrm{CO}_{2}$ from $1 \mathrm{~g}$ of $\left[1{ }^{14} \mathrm{C}\right]$ galactose in amounts similar to those found in control subjects. It was therefore postulated that these patients may have developed an alternative pathway, probably via galactonate and xylulose (reaction 7). Since both these were negroes while the others were white, the patients who can develop such a pathway are known as the 'negro variant'. There is evidence that such a pathway may exist at birth, as for instance in one of two negro sibs who was clinically normal in spite of the complete absence of transferase from the red cells, while the other had all the classical symptoms. 
In a review of galactosaemia in 1962 Woolf quoted some 180 references. Since then many more papers on this subject have been published. This astounding output has resulted in galactosaemia being one of the best documented and understood of all the inborn errors of metabolism, but there are still many problems that await solution.

\section{REFERENCES}

Beutler, E., Baluda, M. C., Sturgeon, P., and Day, R. (1965). Lancet, 1, 353.
Gabbay, K. H., and O'Sullivan, J. B. (1968). Diabetes, 17, 300. Gitzelmann, R. (1965). Lancet, 2, 670.

- (1967). Pediat. Res., 1, 14.

Hansen, R. G., Bretthauer, R. K., Mayes. J., and Nordin, J. H. (1964). Proc. Soc. exp. Biol. (N.Y.), 115, 560.

Heyningen, R. van (1959). Nature (Lond.), 184, 194.

Schwarz, V. (1960a). J. Lab. clin. Med., 56, 483.

(1960b). Arch. Dis. Childh., 35, 428.

Segal, S., Blair, A., and Topper, Y. J. (1962). Science, 136, 150.

Stewart, M. A., Sherman, W. R., Kurien, M. M., Moonsammy, G. I. and Wisgerhof, M. (1967). J. Neurochem., 14, 1057.

Wells, H. J., and Wells, W. W. (1967). Biochemistry (Wash.), 6, 1168. Wells, W. W., Pittmann, T. A., and Egan, T. J. (1964). J. biol. Chem., 239,3192

Woolf, L. I. (1962). Advance. clin. Chem., 5, 1. 